\title{
Effect of Thyroid Hormone on the Histology of Rat Submandibular Salivary Gland During Postnatal Development
}

\author{
Shaher Bano ${ }^{1}$ \\ BDS \\ Sarah Ghafoor ${ }^{2}$ \\ BDS, PhD \\ Nadia Naseem ${ }^{3}$ \\ MBBS, PhD
}

OBJECTIVE: Salivary glands pass through various stages of prenatal and postnatal development. This process is a highly regulated event governed by signaling molecules, growth factors and hormones. Submandibular salivary gland is an excellent model to study salivary gland morphogenesis. It has been reported that alternations in endocrine hormones can affect morphological and functional states of salivary gland formation and for this purpose the current study was designed to investigate the effects of exogenous administration of T3 on the histology of the submandibular salivary gland during early postnatal development.

METHODOLOGY: Following ethical approval, twenty four healthy Wister rats were obtained. Twelve were taken at the age of three weeks and divided into control (A1) and experimental (B1) groups. Remaining twelve were taken at the age of seven weeks and divided into control (A2) and experimental (B2) groups. The experimental animals were administered $0.5 \mathrm{mg} / \mathrm{kg}$ body weight of T3 while controls were given normal saline. The animals of group A1 and B1 were sacrificed at week 5 and those of group A2 and B2 at week nine. The submandibular glands were dissected out and their morphological structure was observed. The combined weight and volume of submandibular and sublingual gland was taken. Hematoxylin and Eosin staining was performed to assess any histological changes in the parenchyma and stromal components of the submandibular salivary gland.

RESULTS: No significant gross and histological changes in parenchyma and stroma of submandibular salivary gland tissue were observed in control and experimental groups at week five and week nine. No statistically significant difference was found in the combined weight and volume of submandibular and sublingual glands through the independent sample t-test.

CONCLUSION: Exogenous administration of T3 at a lower dose did not cause significant changes in the postnatal development of the submandibular salivary gland.

KEY WORDS: Submandibular salivary gland, development, thyroid hormone, postnatal

HOW TO CITE: Bano S, Ghafoor S, Naseem N. Effect of thyroid hormone on the histology of rat submandibular salivary gland during postnatal development. J Pak Dent Assoc 2018;27(1):37-42.

DOI: https://doi.org/10.25301/JPDA.271.37

Received: 11 January 2018, Accepted: 17 January 2018

\section{INTRODUCTION}

$\mathrm{S}$ alivary glands are exocrine glands that produce saliva. There are three pairs of major salivary glands and a large number of minor salivary glands that are present in various parts of the oral cavity. ${ }^{1}$ Two important structural components of salivary glands include the secretory portion (parenchyma) and the connective tissue (stroma). ${ }^{2}$ Salivary glands consist of a connective tissue capsule that surrounds the parenchyma and divides it into lobes and lobules. The parenchyma consists of secretory end-pieces known as the

1. M. Phil Scholar, Department of Oral Biology University of Health Sciences Lahore, Pakistan.

2. Assistant Professor. Department of Oral Biology University of Health Sciences Lahore, Pakistan.

3. Assistant Professor. Department of Morbid Anatomy \& Histopathology, University of Health Sciences Lahore, Pakistan.

Corresponding author: "Dr. Sarah Ghafoor” < sarahghafoor@uhs.edu.pk > acini and a ductal system. The acini are more abundant as compared to the salivary ducts which include the intercalated, striated and excretory ducts. ${ }^{3}$

Unlike humans, in rats, in addition to these ducts, the ductal system also includes the granular convoluted tubules (GCT's). ${ }^{4}$ GTC's are an extension of the striated ducts. They are absent at birth ${ }^{5}$ and begin to develop as budding off from striated ducts during the second and third month of postnatal life.6 They lie between the intercalated and striated ducts. ${ }^{7,8}$ The granular convoluted tubules are named as they are highly convoluted due to the presence of a large number of secretary granules. Previous studies have shown that these granules contain a large number of biologically active peptides including nerve growth factor (NGF), hepatic growth factor (HGF), epidermal growth factor (EGF) and transforming growth factor-alpha (TGF- $\alpha$ ). ${ }^{5,9}$ These growth factors play 
essential roles in development proliferation, differentiation and functions of the salivary glands. The granular convoluted tubules are present only in the rat submandibular gland $(\mathrm{SMG})^{10}$ but they can be induced in the parotid gland by administration of thyroid hormone 11 as their development is under hormonal control. ${ }^{5}$ In rats, submandibular gland is the largest salivary gland ${ }^{12}$ and is used as an excellent model to study various aspects of growth and development of salivary glands. ${ }^{4}$

Thyroid hormone is a trophic hormone that is essential for growth and differentiation. ${ }^{13}$ It promotes postnatal growth and development of organisms. ${ }^{14,15}$ Previous studies have shown that development of rat submandibular glands is affected by many endocrine hormones like androgens, glucocorticoids, estrogens, progesterones, and corticosteroids including thyroid hormone. ${ }^{6,13,16,17}$

The metabolically active form of thyroid hormone is 3 , 3, 5 tri-iodo-thyronine (T3) which induces cyto-differentiation of GCT's precociously thus affecting postnatal development of submandibular salivary glands. ${ }^{5}$ As the rodent salivary glands complete their development postnatally, any alterations in hormones such as T3 can also have an influence on the normal completion of salivary gland development. ${ }^{18}$ Keeping in view the possible hormonal changes induced by T3 on differentiation of salivary GCT's, ${ }^{5}$ the present study was designed to investigate the effects of exogenous administration of thyroid hormone on the histology of submandibular gland during postnatal development.

\section{METHODOLOGY}

\section{Ethical Approval}

This experimental study was conducted at the University of Health Sciences Lahore following ethical approval from the Institutional ethical review committee of the University of Health Sciences Lahore and all the experiments were conducted as per the guidelines set by the committee.

\section{Calculation of sample size}

The sample size was calculated by the following formula keeping the power of study equal to $90 \%$ and level of significance equal to $5 \% .{ }^{10}$

$$
n_{1}=\frac{\left(\mathrm{Z}_{1-\beta}+\mathrm{Z}_{1-\alpha / 2}\right)^{2}\left(\sigma_{1} 2+\sigma_{2} 2\right)}{(\mu 1-\mu 2)^{2}}
$$

Where, $Z_{1-\beta}$ at desired power of $90 \%=1.28, Z_{1-\alpha / 2}$ at desired level of significance of $5 \%=1.96$, estimated mean of group $\mathrm{A}, \mu 1=13$ and, estimated mean of group B, $\mu 2=4$, mean Difference $(\mu 1-\mu 2)=9$, standard deviation of Group $\mathrm{A}(\sigma 1)=2$, standard deviation of group $\mathrm{B}(\sigma 2)=1$, calculated sample size in each group $=1$. The sample size came out as one in each group however it was increased to six in each group according to previous published literature. ${ }^{8}$

\section{Preparation of animals}

A total of twenty four healthy male Wister (Rattus norvegicus) were obtained through non-purposive sampling from the colony maintained at the Experimental Research Laboratory at the University of Health Sciences, Lahore. The pups were reared from birth and were weaned off at day twenty one of age. The rats of age three weeks having weight approximately 50 grams and seven weeks having weight approximately 201-225 grams were used in this study. All animals were housed in a temperature controlled room (23 \pm $\left.2^{\circ} \mathrm{C}\right)$ and humidity $(50 \pm 5 \%)$ was maintained. In order to maintain a stable biological rhythm, constant cycles of having 12-h light and 12-h darkness were applied. The animals received standard rat diet and water ad libitum and were allowed to acclimatize for one week before starting the experiment. Female or pregnant rats and rats suffering from any illness were excluded from the study. Group allocation was done through balloting technique. Out of twenty four rats, twelve were taken at the age of three weeks and divided into control (A1) and experimental (B1) groups. Remaining twelve were taken at the age of seven weeks and divided into control (A2) and experimental (B2) groups. So each group comprised of six animals.

\section{Administration of thyroid hormone}

Freshly prepared 3, 3, 5 tri-iodo-thyronine (T3) (Sigma chemicals) at $0.3 \mathrm{mg} / \mathrm{ml}$ in $0.005 \mathrm{~N} \mathrm{NaOH}$ in $0.9 \% \mathrm{NaCl}$ was used. The dose for mice was $1 \mathrm{mg} / \mathrm{kg}$ body weight ${ }^{11}$ which was adjusted as $0.5 \mathrm{mg} / \mathrm{kg}$ body weight for rats 19 that was given subcutaneously on alternate basis for fourteen days.

\section{Sample collection}

The animals of group A1 and B1 were sacrificed at week five and those of group A2 and B2 at week nine. The animal to be sacrificed was transferred to a plastic jar having a cotton wool soaked in chloroform to euthanize it. The exposed submandibular glands were carefully dissected out, washed with normal saline, weighed together with the sublingual gland for analysis of combined weight and volume.

\section{Tissue processing and histological staining}

All the tissues were subjected to the automatic tissue processor (Microm STP-120) and passed through Xylene and graded concentration of Ethanol at 70\%, 90\% and 100\%. After dehydration, paraffin-embedded wax blocks were obtained by placing in embedding center (Tissue Tek TECTM, Sakura). Sections were cut at a thickness of $6 \mu \mathrm{m}$ by rotary 
microtome (Leica RM 2125RT) and placed on the slides for Hematoxylin and Eosin staining. The slides were immersed twice in Xylene for five minutes. Rehydration was done by immersing the slides in 100\% 90\%, 70\% Ethanol, washed with tap water and dipped in Hematoxylin solution for five minutes. This was followed by immersion in $1 \%$ acid alcohol and $0.2 \%$ ammonia water, until the desired blue color was obtained. The slides were then immersed in $1 \%$ eosin for few minutes and rehydrated by passing through graded series of $70 \%, 80 \%, 90 \%$ and $100 \%$ ethanol and xylene. ${ }^{20}$ They were dried at room temperature and mounted with DPX and cover-slipped. The stained sectioned were visualized under Olympus microscope (BX51TF) with camera (Infinity-1) under 10X and 40x magnification to observe any histological changes in response to administration of T3.

\section{Statistical analysis}

Statistical analysis was conducted using Statistical Package for Social Sciences Version 20 (SPSS-20). Comparison of difference between mean combined weight and volume of the salivary glands was done through the independent sample test. A p-value of $<0.05$ was taken as statistically significant.

\section{RESULTS}

\section{Macroscopic Examination of Submandibular gland}

The gross examination of submandibular (SMG) of both the control (A1, A2) and experimental groups (B1, B2)

Table No.1: Comparison the mean of combined weight and volume of SMG and SLG of control and experimental groups

\begin{tabular}{|c|c|c|c|c|}
\hline Parameter & Groups & Mean weight \pm SD & Std. Error & $\begin{array}{c}\text { Level of } \\
\text { Significance* }\end{array}$ \\
\hline \multirow{4}{*}{ Weight (mg) } & Al & $0.17 \pm 0.008$ & 0.003 & \multirow{2}{*}{0.18} \\
\hline & B1 & $0.16 \pm 0.008$ & 0.003 & \\
\hline & A2 & $0.29 \pm 0.012$ & 0.004 & \multirow{2}{*}{1} \\
\hline & B2 & $0.29 \pm 0.017$ & 0.007 & \\
\hline \multirow{4}{*}{ Volume (ml) } & A1 & $0.20 \pm 0$ & 0.00 & \multirow{2}{*}{0.17} \\
\hline & B1 & $0.17 \pm 0.041$ & 0.017 & \\
\hline & A2 & $0.26 \pm 0.05$ & 0.021 & \multirow{2}{*}{0.54} \\
\hline & B2 & $0.28 \pm 0.040$ & 0.016 & \\
\hline
\end{tabular}

The mean difference of combined weight and volumes of SMG (submandibular gland) and SLG (Sublingual gland) between both the control and experimental groups was found to be almost similar. Independent sample t-test suggested that there is a statistically non-significant difference between the combined weight and volume of SMG and SLG of both the control (A1 and A2) and experimental (B1 and B2). showed that the glands were pink in color, smooth in texture and roughly ovoid in shape. The lobes of the glands were clearly visible and they were enclosed in a connective tissue capsule. There was no gross abnormality noted in all four groups.

Combined weight and volume of the salivary glands In the present study, combined weight of submandibular and sublingual glands was taken as both the glands were placed in the same connective tissue. No significant difference in the combined weight and volume of the glands was noted after T3 administration (Table 1)

\section{Histological Examination of Submandibular salivary gland (SMG)}

The histological analysis of submandibular glands of both the control and experimental (A1, A2) (B1, B2) groups was done at week five and week nine. The glands of both the experimental groups showed similar structure to that of control and hence are described together with details of parenchymal and stromal components.

\section{a) Parenchymal components of SMG of control and experimental groups at week 5 and 9}

The parenchymal components were categorized into lobe architecture, nature and nuclei of acini, ductal epithelium and nuclei and myoepithelial cells. The architecture of lobules of all submandibular salivary glands was completely preserved. Each lobe was observed having acini and completely surrounded by the connective tissue capsule (Fig 1). The serous acini were almost equal in size with

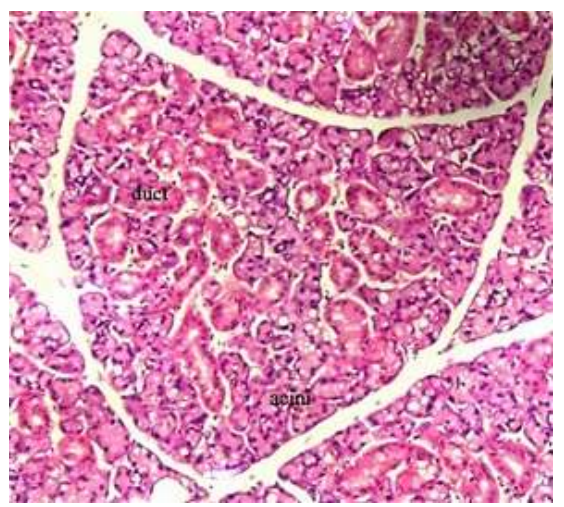

Fig 1: Photomicrograph of Hematoxylin and Eosin stained histological section of SMG showing lobules with preserved architecture containing serous acini and ducts under 10x magnifications

pyramidal shaped cells and dense granular cytoplasm was observed. They appeared to have a regular pattern. The serous acini had a rounded nucleus that was normochromatic 
(Fig 2). The striated and excretory ducts had simple columnar and pseudostratified columnar epithelium. The striated ducts were more numerous as compared to excretory ducts. The nuclei of various ducts appeared round or ovoid in shape and were normochromatic (Fig 2, 3). Myoepithelial cells

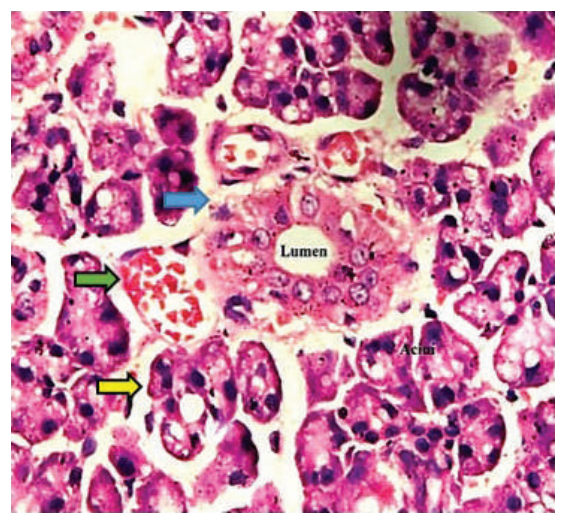

Fig 2: Photomicrograph of Hematoxylin and Eosin stained section of SMG showing pyramidal shaped cells of serous acini with rounded, normochromatic nuclei (yellow arrow), striated duct having simple columnar epithelium (blue arrow), a blood vessel having blood cells (green arrow) under 40x magnification.

appeared as flattened cells associated with the basement membrane of the serous acini. No difference in morphological histology was observed between both controls and experimental groups.

\section{b) Stromal components of SMG of control and experimental groups at week 5 and 9}

The stromal components comprised of connective tissue, adipose cells and the blood vessels. The inter-lobular (between two lobules) and intra-lobular (within the lobules) connective tissue was found to be normal and showed nuclei of the

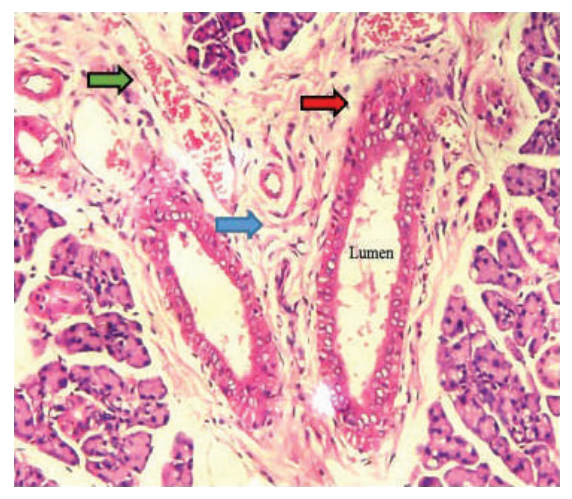

Fig 3: Photomicrograph of SMG illustrating an excretory duct having a large lumen with pseudostratified columnar epithelium and goblet cells (red arrow), intra-lobular connective tissue with fibroblasts (blue arrow), blood vessel with blood cells (green arrow) under 40x magnification.

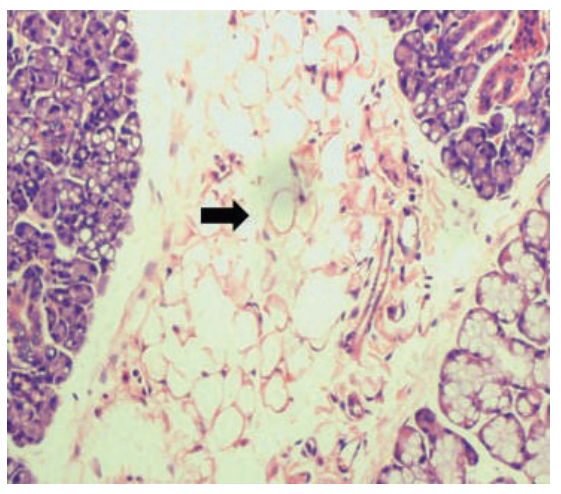

Fig 4: Photomicrograph of SMG showing adipocytes (black arrow) with empty appearing cytoplasm and nucleus pushed to one side giving signet ring appearance under 40x magnification.

fibroblasts and connective tissue fibers. No inflammatory changes were observed in both groups (Fig 3). Blood vessels associated with the ducts within the lobules were visible (Fig 2). They were also present between the lobes associated with the excretory ducts. They appeared normal, lined by single layer of endothelium and contained red blood cells in them (Fig 3). The clusters of adipocytes with clear cytoplasm having signet ring appearance were also observed in the submandibular salivary glands of both control and experimental groups and were found to be similar in appearance in both groups (Fig 4).

\section{DISCUSSION}

Submandibular gland is used as an excellent model to study various aspects of growth and development of salivary glands. ${ }^{4}$ How exogenous administration of T3 affects the morphological or histological development of rat SMG is currently unknown and may provide valuable insights into conditions of hypo- or hyperthyroidism. It has been reported that to function as a mature gland, the rat salivary glands complete their morphological development postnatally by 7 to 10 weeks ${ }^{6,21}$ and during this period alteration in the hormones such as thyroid, androgens and growth hormones also have an influence on the normal completion of salivary gland development. ${ }^{18}$ The gross examination of submandibular salivary glands showed no morphological changes in postnatal development. Thyroid hormone administration to the animals did not affect the weight and volume of both the salivary glands suggesting that exogenous $\mathrm{T} 3$ administration did not have any significant morphological and histological changes in the submandibular salivary glands of both control and experimental animals. These findings are similar to another study on the parotid gland where the parenchymal and stromal elements of both the control and experimental groups were also found to be normal when thyroid hormone was 
administered at low dosage..$^{22}$ This may also be possible as T3 was administered at a dose that was on alternate days and was kept within the physiological limits so it did not lead to any adverse effects. It may be interesting to investigate with higher doses of $\mathrm{T} 3$ and observe cytological changes. The GCT's of submandibular gland are associated with production of various growth factors such as epidermal growth factor (EGF), nerve growth factor (NGF) and transforming growth factor alpha (TGF- $\alpha$ ). ${ }^{5,9}$ These growth factors play essential roles during developmental processes exhibited in salivary glands such as proliferation, differentiation and functions.10 We could not find any morphological differences in histology of SMG in both the experimental groups. It is likely that following T3 administration, compensatory regulation provided by other growth factors involved in salivary gland development such as EGF signaling may also overcome the negative effects of exogenous T3 administration leading to an overall normal development of submandibular salivary glands. ${ }^{23}$

\section{CONCLUSIONS}

Exogenous administration of T3 at a dose of $0.5 \mathrm{mg} / \mathrm{kg}$ did not cause any significant changes in the histology of the submandibular salivary gland.

\section{CONFLICT OF INTEREST}

The authors declare no conflict of interest

\section{ACKNOWLEDGEMENTS}

We would like to thank the animal care staff of the Experimental Research Laboratory at the University of Health Sciences Lahore (UHS) for their facilitation throughout study. We would also like to thank the Library department (UHS) regarding access to relevant books and publications. We thank the Higher Education Commission of Pakistan (HEC) for allowing our university access to the e-Library.

\section{REFERENCES}

1. Zolotukhin S. Metabolic hormones in saliva: origins and functions. Oral Dis. 2013; 19(3):219-29.

https://doi.org/10.1111/odi.12015

2. Pedersen A.M, Bardow A, Jensen S.B, Nauntofte B. Saliva and gastrointestinal functions of taste, mastication, swallowing and digestion. Oral Dis. 2002; 8(3): 117-29.

https://doi.org/10.1034/j.1601-0825.2002.02851.x

3. Kumar, G.S. Orban's Oral Histology and Embryology.

13th ed., New Dehli, Elsevier. 2011.
4. Tucker AS, Miletich I, editors. Salivary glands: development, adaptations and disease. Karger Medical and Scientific Publishers; 2010. https://doi.org/10.1159/isbn.978-3-8055-9407-3

5. Gresik, E.W. Postnatal developmental changes in submandibular glands of rats and mice. J. Histochem. Cytochem. 1980; 28(8): 860-70.

https://doi.org/10.1177/28.8.6160181

6. Wu HH, Kawamata H, Wang DD, Oyasu R. Immunohistochemical localization of transforming growth factor $\alpha$ in the major salivary glands of male and female rats. Histochem J. 1993; 25(9):613-8.

https://doi.org/10.1007/BF00157875

7. Gresik, E.W. The granular convoluted tubule (GCT) cell of rodent submandibular glands. Microsc. Res. Tech. 1994; 27(1): 1-24.

https://doi.org/10.1002/jemt.1070270102

8. Coire F. A. S, Umemura A. L. O, Cestari T. M, Taga R. Increase in the cell volume of the rat submandibular gland during postnatal development. Braz J Morphol Sci. 2003; 20(1): 37-42.

9. Gresik E.W, Hosoi K, Kurihara K, Maruyama S, Ueha T. The rodent granular convoluted tubule cell--an update. Eur J Morphol. 1996; 34(3): 221-4.

https://doi.org/10.1076/ejom.34.3.221.13033

10. Yoshida K, Aiyama S, Uchida M, Kurabuchi S. Role of thyroid hormone in the initiation of EGF (epidermal growth factor) expression in the sublingual gland of the postnatal mouse. Anat Rec A Discov Mol Cell Evol Biol.

2005;284(2):585-93.

https://doi.org/10.1002/ar.a.20197

11. Kurabuchi, S. Repeated androgen and thyroid hormone injection modulates the morphology of hormone-responsive duct cells in the mouse parotid gland. Odontology, 2006; 94(1): 29-37.

https://doi.org/10.1007/s10266-006-0064-2

12. Wang X, Qi S, Wang J, Xia D, Qin L, Zheng Z, Fan Z. Spatial and temporal expression of c-Kit in the development of the murine submandibular gland. J Mol Histol. 2014; 45(4): 381-9.

https://doi.org/10.1007/s10735-014-9570-7

13. Kurabuchi S, Gresik E. W, Hosoi K. Additive and/or synergistic action (downregulation) of androgens and thyroid hormones on the cellular distribution and localization of a true tissue kallikrein, $\mathrm{mK} 1$, in the mouse submandibular gland. J Histochem Cytochem. 2004; 52(11): 1437-46. https://doi.org/10.1369/jhc.4A6333.2004

14. Vachkova EG, Georgiev IP, Bivolarski BL, Konakchieva R. Relationships between plasma concentrations of epidermal growth factor, insulin and iodated thyroid hormones in early and normal weaned rabbits. Revue Méd Vét. 2010; 161(1):30-6. 
15. Moreno M, Lanni A, Lombardi A, Goglia F. How the thyroid controls metabolism in the rat: different roles for triiodothyronine and diiodothyronines. J Physiol. 1997; 505(2): 529-38.

https://doi.org/10.1111/j.1469-7793.1997.529bb.x

16. Rougeot C, Rosinski-Chupin I, Mathison R, Rougeon F. Rodent submandibular gland peptide hormones and other biologically active peptides. Peptides. 2000; 21(3):443-55. https://doi.org/10.1016/S0196-9781(00)00158-3

17. Shafer WG, Muhler JC. Endocrine influences upon the salivary glands. Ann N Y Acad Sci. 1960; 85(1):215-27. https://doi.org/10.1111/j.1749-6632.1960.tb49960.x

18. Ikeda R, Aiyama S, Redman RS. Exogenous thyroid hormone affects myoepithelium and proliferation in the developing rat parotid gland. Biotech. Histochem. 2010; 84(6):267-74.

https://doi.org/10.3109/10520290902984258

19. Reagan-Shaw S, Nihal M, Ahmad N. Dose translation from animal to human studies revisited. The FASEB J. 2008;22(3):659-61.

https://doi.org/10.1096/fj.07-9574LSF
20. Harris H.F. On the rapid conversion of hematoxylin into haematein in staining reactions. J Appl Micros Lab Methods. 1900; 3(3): 777.

21. Young WG, Ramirez-Ya-ez GO, Daley TJ, Smid JR, Coshigano KT, Kopchick JJ, Waters MJ. Growth hormone and epidermal growth factor in salivary glands of giant and dwarf transgenic mice. J Histochem Cytochem. 2004; 52(9):1191-7.

https://doi.org/10.1369/jhc.4A6294.2004

22. Ikeda R, Aiyama S, Redman RS. Effects of exogenous thyroid hormone on the postnatal morphogenesis of the rat parotid gland. Anat Rec. 2008; 291(1):94-104. https://doi.org/10.1002/ar.20620

23. Kashimata, M. and Gresik, E.W. Epidermal growth factor system is a physiological regulator of development of the mouse fetal submandibular gland and regulates expression of the $\alpha 6$-integrin subunit. Dev. Dynam. 1997; 208(2): 149161.

https://doi.org/10.1002/(SICI)10970177(199702)208:2<1 49::AID-AJA2>3.0.CO;2-I 